\title{
KEINDAHAN DI BALIK TRAGEDI
}

\begin{abstract}
I Made Saryana $^{1}$
Abstract : The use of transportation facilities represents the metaphor of "double-sides sword"; on the one hand it gives usefulness, on the other hand it gives destructiveness. An ideal dualism of modern culture achievement, and the tragedy inherently implied. While the comfort of traveling embodies the positive side, the pollution and car accident represent the negative side. We have no other alternative, nevertheless, since the modern culture demanded such a high mobility that the use of modern transportation is unavoidable.

Almost everyday we heard and read in mass media about various accident of car crashes. Even in minor cases, the victims or damages are always unavoidable. In a huge scale, the accident of transportation might take a great many victims and material damages. Consequently, the survivors or the relatives of the casualties might experience mourning and sadness, even trauma. These are what we might call tragedies, the ones causing human suffering.

Viewed as an event, accident left at least two realities: the one associated with mental/psychological implication and the other related to the factual objects that create automatically new "meaning", even transformation to other "meaning". In my opinion, the wrecked cars, or those with the paint peeled off, or the chassis detached, or the whole body burnt out, represent the factual reality of the objects undergone the transformation of "meaning". A paradoxical reality of meaning: Between the one referring to the traumatic side, and the other that signify the visually artistic side. It is on this paradoxical meaning that I based my creative exploration to create my photographic artworks. Observation might inspire an unexpected visual composition.

By photographing the most unique and the most interesting of the broken pieces of the wrecked cars using the close-up function, an artistic and aesthetical photographic artwork might be created. That is the reason for me to choose the title "Beauty behind Tragedy".
\end{abstract}

Key words: photographic artworks, tragedy and beauty.

Berawal dari ketidaksengajaan, sekitar bulan November 2005, ketika saya dalam suatu perjalanan menuju Gunung Kidul untuk melakukan persembahyangan, di kanan kiri Jalan Wonosari selintas terlihat tumpukan mobil ringsek bekas tabrakan berserakan, berwarna-warni dengan berbagai merek. Hal tersebut mengusik pikiran saya untuk melakukan pengamatan khu-

${ }^{1}$ I Made Saryana adalah Dosen pada Program Studi Fotografi Fakultas Seni Rupa dan Desain Institut Seni Indonesia Denpasar. 
sus lebih mendalam. Dermawan (1994:12) menyatakan, 'seperti halnya pelukis hiperrealis Amerika yang tersohor yaitu Andrew Wyeth juga sering menciptakan karya dengan mengetengahkan objek-objek unik, yang tak diperhatikan orang', Memang banyak sekali hal-hal yang dianggap sebagian besar orang sebagai sesuatu yang tidak berguna tetapi oleh seniman yang kreatif justru sebaliknya. Benda-benda seperti itu bisa saja diolah atau didaur-ulang kembali menjadi sesuatu yang 'baru', bernilai dan bermanfaat, atau dijadikan inspirasi dalam penciptaan karya seni.

Dalam memantapkan tema ini, saya melakukan pengamatan lagi ke beberapa kantor Polisi, baik di Yogyakarta maupun di Bali. Biasanya di kantor-kantor Polisi tersebut terdapat tempat penampungan kendaraan bekas tabrakan. Di tempat ini, puluhan mobil dan ratusan sepeda motor berserakan begitu saja dalam keadaan ringsek, hancur berkeping-keping, penyok, bercat aus kena hujan dan teriknya matahari, hingga benda yang sebelumnya berharga puluhan hingga ratusan juta menjadi tidak berharga lagi.

Transportasi telah berkembang menjadi salah satu kebutuhan manusia yang paling mendasar. Itulah sebabnya, mulai dari kegiatan tunggal yang paling sederhana sampai kegiatan hidup yang multicorak, transportasi selalu menjadi bagian yang penting. Transportasi dapat diartikan sebagai usaha memindahkan, menggerakan, mengangkut, atau mengalihkan suatu objek dari satu tempat ke tempat lain, di mana objek tersebut lebih bermanfaat atau dapat berguna untuk tujuan-tujuan tertentu (Miro, 2005: 4).

Kemajuan ilmu pengetahuan dan teknologi, mempercepat proses perkembangan di bidang transportasi yang dari waktu ke waktu terus berkembang sesuai dengan kebutuhan masyarakat. Misalkan dari orang berjalan kaki kemudian dapat menaiki sepeda, motor, mobil, transportasi laut maupun pesawat terbang, sehingga jarak dari satu pulau ke pulau lain atau jarak dari satu negara ke negara lain, bukanlah menjadi hambatan lagi.

Disadari bahwa kemajuan di bidang transportasi telah banyak memberikan dampak yang positif bagi kehidupan manusia, namun ternyata juga diiringi oleh dampak negatif yang dapat merugikan diri manusia sendiri. Polusi udara adalah salah satu contoh sisi negatif yang disebabkan akibat pembuangan gas dari pembakaran alat-alat transportasi saat ini. Contoh lain adalah tragedi kecelakaan sepeda motor, mobil, kereta api, jatuhnya pesawat terbang, bahkan tenggelamnya kapal di lautan yang tentunya juga menimbulkan kerugian material maupun korban manusia yang dapat menyebabkan cacat ataupun kematian. Penggunaan alat-alat transportasi tersebut ibarat sebuah "pedang bermata dua", di satu sisi memberikan manfaat dan di sisi lain dapat menghancurkan.

Rapuhnya tatanan transportasi Indonesia yang dikembangkan tanpa landasan riset teknologi dan kebijakan kuat, memunculkan berbagai persoalan yang mengancam keselamatan dan keamanan pengguna jasa angkutan. Dari data lakalantas tercatat lebih dari 30.000 orang mati dan 1,2 juta 
orang luka-luka setiap tahunnya. Sepeda motor yang merupakan $72 \%$ dari jumlah kendaraan di Indonesia, sebagai penyumbang terbesar yaitu $73 \%$ dari kecelakaan. (Parikesit, 2007: 1-2)

Terjadinya kecelakaan disebabkan oleh beberapa hal seperti: faktor kerusakan pada salah satu bagian kendaraan dan faktor manusia yaitu: kelalaian dari pengendara, mabuk, mengantuk, ketidakdisiplinan, melanggar rambu-rambu lalu lintas atau karena sempitnya jalan dan sebagainya.

Sebagai peristiwa, kecelakaan menyisakan paling tidak dua realitas, antara yang berkaitan dengan implikasi mental/psikologis, dan lainnya menyangkut fakta-fakta benda yang secara otomatis menciptakan "makna" baru, atau malah peralihan ke "makna" lain.

Bagi saya, realitas benda-benda dari mobil yang penyok, cat mengelupas, hingga struktur kendaraan yang tergeletak, atau hangus terbakar, adalah realitas fakta benda yang telah mengalami peralihan "makna'. Sebuah realitas makna paradoks; antara makna yang menunjuk ke sisi traumatik, dan makna yang menunjuk ke artistik visual. Pada makna paradoks inilah, saya menempatkan eksplorasi kreatif penciptaan karya fotografi saya. Berdasarkan pengamatan saya, tercipta sebuah komposisi visual yang tak terduga, ketika kendaraan yang sebelumnya (pra-peristiwa) dikonstruksi dengan sedemikian bagusnya tiba-tiba bertabrakan hingga memunculkan efek: ringsek, penyok, maupun hancur berkeping-keping namun unik dan menarik. Di sinilah saya melihat "makna keindahan" di balik sebuah tragedi.

Dengan memilih bagian-bagian tersebut yang paling unik dan menarik untuk difoto dengan meng-close up objek tersebut maka terciptalah karya fotografi yang memiliki nilai estetik dan artistik yang khas, maka tajuk penciptaan karya fotografi tugas akhir ini adalah "Keindahan di Balik Tragedi".

Berdasarkan penjelasan pada bagian latar belakang penciptaan, maka ide penciptaan dapat dirumuskan sebagai berikut: Bagaimana proses penciptaan karya fotografi yang berdasar pada pemahaman keindahan di balik tragedi dengan mengeksploitasi subjek fakta benda sebagai akibat kecelakaan transportasi (mobil ringsek, penyok, pecah dan sebagainya) dapat divisualisasikan menjadi karya fotografi ekspresi yang kreatif.

Sedangkan orisinalitas dalam karya saya adalah: menampilkan sisi keindahan bagian-bagian mobil yang ringsek akibat kejadian tabrakan, yang menekankan pada komposisi bentuk, warna, tekstur, garis, bidang dengan memanfaatkan ikon-ikon yang ada sehingga tercipta karya estetik kreatif. Walaupun sebelumnya telah ada seniman yang memanfaatkan mobil sebagai tema dalam karya-karyanya, baik karya lukis maupun karya fotografi, hal ini dapat dipastikan memiliki perbedaan dari ide/konsep maupun visualnya. 


\section{PENGERTIAN FOTOGRAFI}

Secara umum pengertian fotografi adalah seni dan proses penghasilan gambar dengan cahaya pada film atau permukaan yang dipekakan (Giwanda, 2002: 13). Kalau dalam seni lukis digunakan media kuas dan cat, sedangkan dalam fotografi menggunakan kamera dan cahaya untuk menghasilkan karya.

Istilah Fotografi (Photography) berasal dari bahasa Latin, yakni : "photos" dan "graphos". Photos artinya cahaya atau sinar, sedangkan graphos artinya menulis atau melukis. Jadi, arti sebenarnya dari fotografi adalah proses dan seni pembuatan gambar (melukis dengan sinar atau cahaya) pada sebuah bidang film atau permukaan yang dipekakan. Gambar yang dihasilkan diharapkan sama persis dengan aslinya, hanya dalam ukuran yang jauh lebih kecil (Nugroho, 2006: 250).

Di Indonesia akhir-akhir ini, fotografi mengalami perubahan yang cukup signifikan, ditandai adanya kebutuhan masyarakat akan fotografi yang semakin meningkat dan menggairahkan. Terlebih-lebih ditemukannya teknologi digital, yang memberikan kemudahan pada cara merekam dan mencetak gambar sehingga waktu dan biaya dapat dihemat.

Fotografi digital adalah teknologi terbaru dalam bidang fotografi yang memanfaatkan data digital dalam proses pengolahan dan penyimpan datanya. Data digital adalah data berupa angka (digit) 0 dan 1 yang hanya bisa dimengerti oleh komputer. (Nugroho, 2006: 102).

Jadi pada hakikatnya fotografi digital adalah fotografi dengan memanfaatkan komputer sebagai penerjemah gambar, kamar gelap, pencetakan dan juga proses penyimpanannya. Komputer di sini bisa meliputi sebuah mikroprosesor yang ada di dalam kamera, sampai dengan komputer dalam arti sesungguhnya.

Secara umum fungsi fotografi dibedakan menjadi 4 yakni: Fotografi Dokumentasi, Fotografi Jurnalistik, Fotografi Komersial dan Fotografi Ekspresi (seni). Dalam Tugas Akhir ini, karya yang saya ciptakan termasuk dalam katagori foto ekspresi/seni, oleh karena itu maka perlu dikemukakan pengertiannya.

Fotografi Ekspresi, merupakan karya seni sebagaimana karya seni rupa murni, yang juga tampil sebagai karya individual dan kreatif. Dikatakan individual karena dengan eksperimen kreatif mampu menunjukkan karakter pribadi dan memiliki bobot nilai estetika yang dapat dinilai secara utuh sebagai suatu kreteria estetika dalam suatu penciptaan ide maupun konsep yang mendasari. (Marah, 2002:7) Mengatakan bahwa fotografi sekarang cenderung menyuarakan ekspresi seni pribadi dari para pemotretnya, dan 
nyaris meninggalkan fungsi dokumentasi dan imitasi yang selama ini diembannya. Dalam buku Pot-Pourri Fotografi, fotografi ekspresi adalah :

Sebuah karya fotografi yang dirancang dengan konsep tertentu dengan memilih ojek foto yang terpilih dan yang diproses dan dihadirkan bagi kepentingan si pemotretnya dengan luapan ekspresi artistik dirinya, maka karya tersebut bisa menjadi sebuah karya fotografi ekspresi. Dalam hal ini karya fotografi tersebut dimaknakan sebagai suatu medium ekspresi yang menampilkan jati diri si pemotretnya dalam proses berkesenian penciptaan karya fotografi seni. Karya fotografi yang diciptakannya lebih merupakan karya seni murni fotografi (fine art photography) karena bentuk penampilannya yang menitik beratkan pada nilai ekspresif-estetis seni itu sendiri (Soedjono, 2006: 27).

Sejak ditemukannya teknologi fotografi yang mampu merekam objek secara realistik oleh Louis Jacques Mande Daugerre pada tahun 1839 fotografi terus berkembang seiring dengan perkembangan jaman dan dengan penemuan berbagai teknologi fotografi. Berbagai eksperimen dilakukan oleh para photografer untuk menciptakan karya-karya fotografi baik tema dan teknik-teknik visualisasinya yang tercipta melalui atau tanpa kamera.

\section{KEINDAHAN}

Tiga unsur estetik dalam struktur setiap karya seni adalah: Keutuhan atau kebersatuan (unity), Penonjolan atau penekanan (dominance), Keseimbangan (balance) (Djelantik, 2004: 37). Kata struktur mengandung arti bahwa di dalam karya seni itu terdapat suatu pengorganisasian, penataan, ada hubungan tertentu antara bagian-bagian yang tersusun itu.

Selanjutnya Read (1968: 18), mengungkapkan:

... all artists have this same intention, the desire to please; and art is most simply and most usually defined as an attempt to create pleasing forms. Such forms satisfy our sense of beauty and the sense of beauty is satisfied when we are able to appreciate a unity or harmony of formal relations among our sense-perceptions.

...semua seniman memiliki maksud yang sama, keinginan untuk menyenangkan; dan seni pada umumnya didefinisikan sebagai upaya untuk menciptakan bentuk-bentuk yang menyenangkan. Bentuk-bentuk tersebut memenuhi rasa keindahan kita dan rasa keindahan terpenuhi ketika kita mampu memahami kesatuan atau keselarasan hubungan formal antar persepsi inderawi kita.

Read dalam Dharsono, (2004: 4), juga merumuskan keindahan sebagai kesatuan dari hubungan bentuk yang terdapat di antara pencerapan inderawi kita (beauty is unity of formal relations among our sense-perceptions). Jadi keindahan adalah kesatuan hubungan-hubungan kebentukan yang ada 
di antara kesadaran persepsi kita. Bahkan sesuatu yang disebut jorok bisa termasuk di dalamnya, misalnya seonggok sampah atau bahkan kotoran yang masih baru yang kebetulan secara visual menarik.

Ada dua teori tentang keindahan yaitu yang bersifat objektif dan subjektif. Keindahan yang obyektif menempatkan keindahan pada benda yang dilihat. Sedangkan keindahan subjektif ialah keindahan yang ada pada mata yang memandang (Dharsono 2004: 10).

Pemahaman tentang keindahan dalam karya seni diapresiasi berbeda oleh masing-masing individu, karena mereka memiliki kemampuan dan pengalaman estetis yang berbeda sehingga sangat subyektif sifatnya. Berbeda dengan keindahan yang sifatnya obyektif, kemungkinan semua individu merasakan keindahan yang sama terhadap obyek yang sama pula.

\section{TRAGEDI}

Kata tragedi berasal dari Yunani yaitu "Tragoidia" yang artinya nyanyian sendu (Shadily, 1984:3608). Tragedi biasanya banyak digunakan sebagai tema dalam seni pertunjukan baik drama, film, tari ataupun pertunjukan lainnya. Biasanya menyangkut tentang tingkah laku dan peristiwa kemanusiaan, tentang masalah moral, arti eksistensi manusia, hubungan antara sesama manusia dengan dewa-dewa dan lain sebagainya.

Dalam jeda jiwa seperti ini, mungkin berguna jika merenung tentang cahaya-cahaya bencana. Bagi banyak jiwa, bencana identik dengan kematian, perpisahan, kesedihan, duka cita. Dan tentu saja ini teramat manusiawi. Sedikit jiwa yang mau menggali lebih dalam jika di balik bencana ada sejumlah langit kehidupan yang tersingkap rahasianya (Prama, 2007: 7).

Apa yang diungkapkan oleh Prama di atas sangatlah benar adanya bahwa tidak banyak orang mau melihat sisi-sisi kebaikan dari sebuah peristiwa tragis yang terjadi di masyarakat. Kejadian-kejadian tersebut kerap hanya dipandang sebagai sesuatu yang negatif semata bahkan sering dianggap sebagai dosa, kutukan dan sebagainya.

\section{PERALIHAN MAKNA}

Berawal dari melihat, kemudian melakukan pengamatan lebih seksama terhadap artefak/fakta benda (mobil ringsek) yang merupakan dampak kecelakaan kendaraan bermotor, maka saya menginterpretasikan di balik tragedi ada keindahan yang tersembunyi, bukan pada peristiwanya akan tetapi pada artefak yang ditinggalkan. Interpretasi ini merupakan upaya melihat makna baru dari peristiwa ini, yaitu makna positif di balik sesuatu yang negatif atau peralihan dari makna tragedi ke makna keindahan. 
Sebagaimana kenyataan sosial, hal yang disebut indah atau apakah keindahan itu sendiri adalah hasil penafsiran para seniman, kolektor, kritikus seni, penguasa, pengusaha, atau sejarahwan. Berdasarkan perspektif tafsir, kenyataan bukan sesuatu yang bersifat obyektif, jadi, dan selesai, tetapi selalu dalam proses bermakna tergantung pada hubungan diri kita dan kenyataan. (Marianto, 2004: 49).

Sesuatu yang paradoks kemungkinan selalu hadir pada setiap peristiwa, karena sisi positif dan negatif ini merupakan dualitas yang sulit dipisahkan. Prama (2007:7), juga menjelaskan tentang dualitas yakni: Tidak saja kebahagiaan yang menyirami kehidupan, kesedihan juga menyirami, terutama karena kesedihan gurunya sikap rendah hati dan mawas diri. Siapa saja bisa melihat keindahan dalam setiap unsur dualitas (bahagia-bencana, untung-rugi, suci-kotor, dipuji-dicaci), dia berada di depan gerbang pencerahan, kemudian hatinnya menyanyi "semuanya indah".

\section{Landasan Penciptaan}

Penciptaan karya seni ini didasarkan pada perasaan dan dorongan hati yang sangat kuat. Dorongan tersebut muncul karena pengalaman estetik yang dirasa ketika mengamati tumpukan mobil ringsek. Tom Kelley (dalam Marianto, 2006:56), menyatakan bahwa begitu kita mulai mengamati dengan cermat, segala macam pemahaman dan peluang akan terbuka. Lebih lanjut Marianto (2006:iv) menyatakan bahwa segala sesuatu itu baru ada ketika ia diamati. Segala sesuatu itu sudah ada tapi cuma kita tidak melihat sebelumnya. Realitas apa saja, misalnya bergayut pada bagaimana ia dipandang dan dimaknai. Maka dari suatu karya/wacana/ ilmu pengetahuan atau apa saja baru ada ketika ia diamati.

Kalau dipandang dari filosofisnya, keberadaan alat-alat transportasi memiliki kesamaan dengan keberadaan alam/manusia di mana semuanya harus berputar sebagaimana sebuah siklus kehidupan, yakni; dari diciptakannya, dipelihara, kemudian akhirnya rusak. Sebuah proses daur ulang untuk menciptakan sesuatu yang baru; seperti yang tersurat dalam kitab suci Hindu yaitu: Weda dan Upanishad, bahwa kehidupan ini adalah sebuah siklus di mana ada lahir, hidup dan mati. Hal tersebut disimbolkan dengan keberadaan Tuhan dalam tiga manifestasinya yaitu Dewa Brahma (pencipta), Dewa Wisnu (pemelihara) dan Dewa Siwa (pelebur/pemusnah) yang sering disebut dengan Trimurti. (Suseno (2006:30).

Terkait dengan wujud karya fotografi ekspresi yang saya ciptakan, jika dilihat dari aspek visualnya, karya tampil bukan dalam objek yang utuh (keseluruhan), tetapi lebih merupakan salah satu bagian kendaraan (mobil) yang ringsek. Bahkan kadang-kadang tampil tanpa dikenali obyek aslinya sehingga penampilannya yang kecendrungan dalam bentuk abstrak. 
Kencendrungan abstrak dalam karya seni rupa, yaitu abstrak sebagai corak dan abstrak sebagai isme. Kata abstrak mengandung arti tidak berwujud, tidak berbentuk, mujarad, niskala (Partanto,1994:3). Soedarso (1998: 79) berpendapat, bahwa gaya, corak atau langgam ataupun style (stijl), adalah sebenarnya berurusan dengan bentuk luar sesuatu karya seni. Sedangkan aliran, faham atau isme lebih menyangkut pandangan atau prinsip yang lebih dalam sifatnya. Lebih lanjut Soedarso (2000:123) menjelaskan mengenai seni abstrak adalah:

Dalam pengertian yang paling murni abstrak adalah ciptaan-ciptaan yang terdiri dari susunan garis, bentuk dan warna yang sama sekali terbatas dari ilusi atas bentuk-bentuk di alam. Namun secara lebih umum, ialah seni di mana bentuk-bentuk alam itu (kalau ada) tidak lagi berfungsi sebagai objek ataupun tema yang harus dibawakan, melainkan tinggal sekedar sebagai motif saja, sebagai dalih untuk membuat sesuatu...dari pada tidak berbuat apa-apa.

Berkaitan dengan pengertian corak dan aliran tersebut, maka bagi saya dalam menciptakan karya fotografi seni, abstrak adalah sebagai corak, dalam arti lebih berkaitan dengan aspek fisiknya.

Berdasarkan pengamatan terhadap fakta benda mobil ringsek seperti pecah, cat terkelupas bahkan hancur berkeping maka karya akan diwujudkan melalui pengolahan komputer secara terbatas, bahkan lebih dominan tampil apa adanya. Foto yang akan diolah di komputer hanya sebatas mengubah level, ketajaman warnanya dan juga melakukan beberapa koreksi jika ada elemen formal menggangu kesatuannya, dengan menghilangkan atau menambah bagian-bagian yang dimaksud. Pengolahan komposisi elemen formal karya dilakukan pada saat pemotretan, di mana sebelum pemotretan, dilakukan pertimbangan dengan seksama sebelum melepas tombol rana.

Untuk lebih jelasnya, perlu kiranya dikutip pejelasan Darmaprawira tentang masalah komposisi, yakni:

Komposisi (composition) dari kata kerja to compose yang berarti mengarang, menyusun atau menggubah, biasanya digunakan dalam kegiatan seni, sastra, musik ataupun seni rupa, jadi hal ini berhubungan dengan keindahan. (2002:65).

Jadi komposisi diartikan sebagai penempatan atau penyusunan bagian-bagian sebuah gambar untuk membentuk kesatuan dalam sebuah bidang tertentu sehingga enak dipandang. Dengan komposisi yang baik, akan menimbulkan dampak yang lebih kuat dan artistik pada karya. Jadi, komposisi foto merupakan salah satu cara bagaimana fotografer meng-ekspresikan dirinya. 


\section{Proses Penciptaan}

Dalam penciptaan karya fotografi ini, secara sistematis melalui beberapa tahapan yakni: eksplorasi (pengamatan, proses pemotretan), proses kamar terang (seleksi awal, mengoreksi, eksperimen), seleksi akhir dan pencetakan serta upaya penampilan akhirnya.

\section{Tahap Eksplorasi}

Eksplorasi dilakukan dengan mengamati dan memotret di beberapa tempat seperti: tempat bedah mobil tua maupun bekas tabrakan berat di jalan Wonosari dan di tempat penampungan kendaraan bekas tabrakan di beberapa kantor polisi seperti: di depan Gramedia Yogyakarta, Polres Bantul dan di kantor polisi yang ada di Kota Denpasar, Tabanan dan Gianyar serta bengkel-bengkel pengecatan /perbaikan kendaraan bekas tabrakan.

Dalam pemotretan saya menggunakan kamera digital Cannon $350 \mathrm{D}$ dengan menggunakan lensa normal EFS 18-55 mm. Waktu pemotretan dilakukan pada pagi hari, antara jam 08.00 sampai 09.30 jika memotret di kantor-kantor Polisi. Sedangkan pemotretan yang di bengkel-bengkel mobil dilakukan pada pagi hari antara jam 08.00 sampai 09.30 atau sore hari antara jam 15.00 sampai jam 16.30. Pemotertan di siang hari sangat dihindari karena cahayanya terlalu kuat dan cendrung menghasilkan gambar yang datar. Pengambilan gambar dilakukan dengan meng-close up dan single exposure dengan memilih bagian tertentu dari objek yang unik dan menarik.

\section{Tahap Proses Kamar Terang}

Pada tahap ini, dilakukan seleksi awal, koreksi gambar, dan eksperimen. Penyeleksian dan koreksi gambar serta eksperimen dilakukan melalui komputer dengan menggunakan program adobe photoshop 7.0. Berikut ini akan dijelaskan lebih rinci tahapan-tahapan yang dilakukan yaitu:

1. Seleksi awal, selesai pemotretan data dari memory card langsung ditransper ke komputer. Hasil pemotretan, diseleksi dengan memilih gambar yang berkualitas dan disimpan dalam satu folder, sisanya dibuang.

2. Koreksi, dari hasil seleksi tadi kemudian dikoreksi, misalnya ketajaman atau kecerahan gambarnya dengan mengubah level sesuai dengan keinginan. Kemudian mengubah posisi gambar dari horisontal menjadi vertikal atau sebaliknya tergantung posisi gambar, sehingga gampang dilihat. Kroping juga kadang-kadang dilakukan dengan membuang bagian gambar yang tidak diperlukan.

3. Eksperimen, setelah dilakukan tahap seleksi dan koreksi selanjutnya mulai melakukan eksperimen dengan memilih gambar yang kira-kira sesuai dengan tujuan dan ide atau konsep penciptaan. Dalam eks- 
perimen ini dibuat beberapa variasi gambar sebanyak mungkin, sehingga karya dapat dipilih yang terbaik.

Untuk memaksimalkan hasil pengolahan ini saya memanfaatkan fasilitas program photoshop yang disuaikan dengan fungsi masing-masing seperti:

- Lasso tool, polygonal lasso tool digunakan untuk melakukan seleksi gambar.

- Crop tool digunakan untuk mengkroping atau membuang bagian gambar yang tidak perlu.

- Patch tool digunakan untuk menambal bagian-bagian buruk pada foto dengan bagian yang baik.

- Eraser tool digunakan untuk menghapus bagian-bagian gambar yang tidak dikehendaki seperti background.

- Zoom tool digunakan untuk memperbesar / memperkecil kotak/gambar sehingga gambar mudah dilihat untuk diseleksi dan dikoreksi.

- Duplicate layers untuk menggandakan gambar.

- Stamp tool digunakan untuk memperbaiki daerah yang memiliki sisi tajam atau berpola. Tool ini berguna untuk menggandakan atau mengklon bagianbagian gambar ke daerah lain.

- Clone stamp untuk memperbanyak objek, seperti misalnya pada saat membuat gambar agar lebih lebar yang sekaligus dapat berfungsi sebagai bingkai, karena seluruh karya tugas akhir ini tanpa menggunakan pigura. Dan hasil penggandaan objek tadi akan berfungsi sebagai bingkai ketika gambar telah ditempel pada spantram.

- Menu layer kemudian new adjustment layer kemudian dipilih levels untuk merubah ketajaman gambar.

- Color balance digunakan jika menginginkan perubahan warna.

- Platten image untuk mempatenkan gambar.

- Marge layers digunakan untuk menggabungkan dua gambar atas dengan yang dibawahnya.

\section{Seleksi Akhir dan Pencetakan}

Dari hasil pengolahan di atas tadi, kemudian diseleksi akhir yang telah dianggap memenuhi syarat, disimpan dalam satu folder. Setelah terkumpul beberapa gambar baru ditransper ke cd, atau plashdisk sebagai file cadangan yang akan digunakan sebagai bahan konsultasi. Hal ini penting dilakukan untuk menghindari hilangnya file yang ada di komputer jika sewaktu-waktu ada masalah. Setelah beberapa gambar disetujui dosen pembimbing kemudian gambar tesebut dicetak dengan ukuran $8 \times 12 \mathrm{~cm}(3 \mathrm{R})$ tujuannya untuk meyakinkan bahwa ketika gambar telah dicetak hasilnya kelihatan lebih nyata. Sehingga ketika akan dicetak lebih besar, tidak ada rasa keragu-raguan terhadap hasilnya. Hasil cetak 3R tadi dikonsultasikan kembali pada dosen pembimbing, setelah disetujui maka gambar yang terpilih tadi dicetak lebih besar lagi yaitu dalam ukuran yang bervariasi. Semua karya dicetak dengan menggunakan vinil dengan pertimbangan gambar 
dapat dicetak dalam ukuran besar dengan biaya yang relatif terjangkau; untuk ukuran 1 x 1 meter seharga Rp 120.000; dengan menggunakan printer Mimaki dan vinil untuk cetakan ruang luar (outdoor) buatan Korea.

\section{Penampilan Akhir End-product-nya}

Dalam Tahap ini, saya menampilkan karya semaksimal mungkin sebab penampilan sangat mempengaruhi dari keseluruhan karya. Karya telebih dulu dibentang dengan menutup sisi-sisi bagian luar spanram yang nantinya sebagai pigura, kemudian baru disusun bervariasi. Spanram ditutup dengan triplek untuk menjaga keamanan karya, misalnya jika sewaktu-waktu ditekan atau dipegang sehingga kerusakan karya dapat dihindari.

Karya dipamerkan di ruang pameran kampus Program Pascasarjana ISI, bertempat di Jalan Suryodiningratan no. 8. Yogyakarta. Sebelum mengadakan pameran terlebih dahulu dibuat katalog dengan ukuran $45 \times 16 \mathrm{~cm}$, poster yang akan ditempel di beberapa tempat dengan ukuran $32 \times 47 \mathrm{~cm}$, banner dengan ukuran 150 x $60 \mathrm{~cm}$ dan spanduk dengan ukuran $200 \times 75 \mathrm{~cm}$ yang digunakan sebagai sarana publikasi kepada masyarakat. Selanjutnya adalah pemajangan, dengan mengatur karya dan lighting dengan baik.

\section{SIMPULAN}

Penciptaan Karya fotografi ekspresi/seni yang bertajuk "Keindahan di Balik Tragedi" ini, merupakan karya seni yang tercipta dari faktor internal dan eksternal, melalui suatu proses yang cukup panjang. Penciptaan ini sebagai wujud ungkapan pribadi tentang pengalaman estetis yang saya rasakan ketika mengamati fakta benda yang tercipta akibat tragedi tabrakan kendaraan, di mana telah tercipta komposisi elemen formal yang unik dan menarik secara tidak sengaja. Hal tersebut berawal dari ketidaksengajaan melihat tumpukan mobil ringsek yang ada di jalan Wonosari, sehingga imajinasi mulai terbangun. Untuk memantapkan ide tersebut di atas, dilakukan pengamatan yang lebih mendalam ke berbagai tempat seperti di tempat penampungan mobil/kendaraan bekas tabrakan yang ada di kantor-kantor Polisi dan bengkel-bengkel pengecatan/perbaikan kendaraan bekas tabrakan. Pengalaman akan pengamatan pula telah membukakan ruang bagi saya untuk menginterpretasikan bahwa di balik tragedi kecelakaan ternyata menciptakan makna baru yakni makna "keindahan" pada fakta benda yang ditinggalkannya bukan pada dampak tragedinya yang trahumatik. Sebuah peralihan makna baru, dari makna negatif ke makna yang positif.

Perwujudan ide dilakukan melalui berbagai tahapan yakni: eksplorasi (pengamatan, proses pemotretan), proses kamar terang (seleksi awal, mengkoreksi, eksperimen), seleksi akhir dan pencetakan serta upaya penampilan akhirnya. 
Mengingat pemotretan dilakukan dengan meng-close up objek sehingga kadang-kadang objek asli sulit dikenali, maka visual karya terwujud kecendrungan dalam corak abstrak. Penampilan karya dengan tanpa menggunakan pigura tetapi menggunakan spanram tebal dengan membungkus/menutup pinggirannya dengan karya. Hal ini dilakukan dalam upaya mewujudkan aspek tiga dimensi walaupun secara dominan masih tampil dalam dua dimensi.

Pemaknaan karya sangat tergantung dari ikon-ikon visual yang nampak, sehingga pemaknaan sering tidak terkait dengan tragedi kecelakaan.

\section{DAFTAR RUJUKAN}

Ajidarma, Seno Gumira. (2002), Kisah Mata, Fotografi Antara Dua Subyek, Perbincangan Tentang Anda, Galang Press, Yogyakarta.

Clarke, Graham. (1997), The Photograph, Oxford University Press, New York.

Data Kepolisian Negara Republik Indonesia, (2005), Daerah Istimewa Yogyakarta.

Data Kepolisian Negara Republik Indonesia, (2005), Daerah Kota Denpasar.

Djelantik, A.A.M. (2004), Estetika Sebuah Pengantar, Masyarakat Seni Pertunjukan Indonesia, Denpasar.

Darmaprawira, Sulasmi W.A. (2002), Warna, Teori dan Kreativitas Penggunaannya, ITB, Bandung.

Dharsono, Sony Kartika. Pengantar Estetika, Rekayasa Sains, Bandung, 2004.

Fotografi Seni Kusnadi, (1994), Dinas Kebudayaan DKI Jakarta, Jakarta.

Gie, The Liang. (2004), Filsafat Keindahan, Pusat Belajar Ilmu Berguna, Yogyakarta.

Giwanda, Griand. (2002), Panduan Praktis Menciptakan Foto Menarik, Puspa Swara, Jakarta.

Han, Leonardi, CNPS, Hon, PAF. (1998), Sejarah Fotografi, Bandung.

Hardiman, F. Budi. (2005), Memahami Negativitas, Penerbit Buku Kompas, Jakarta.

Hartoko, Dick. (1984), Manusia dan Seni, Kanisius, Yogyakarta.

Indonesia Directory of Photography, (2003), PT Prima Infosarana Media, Jakarta.

Kata Hati Agus Leonardus, (1995), Bentara Budaya, Katalogus pameran, Yogyakarta.

Katalog Bienale Seni Rupa, (1997), Yogyakarta.

Langford, Michael. (1981), The Book of Special Effects Photography, Alfred A. Knopf, New York.

Marah, Surisman. ((1996), Dari Camera Obscura Sampai Digital, Institut Seni Indonesia, Yogyakarta. . (2002), Fotografi Sebagai Media Ekspresi, Yogyakarta. . 2002), Satu Setengah Abad Fotografi di Indonesia, Yogyakarta.

Marianto, M Dwi. (2004), Teori Quantum, Lembaga Penelitian ISI Yogyakarta, Yogyakarta. . (2006), Quantum Seni, Dahara Prize, Semarang.

Miro, Fidel. (2002), Perencanaan Transportasi, Erlangga, Jakarta.

Nugroho, R. Amin. (2006), Kamus Fotografi, ANDI, Yogyakarta. 
Parikesit. (2007). Menggagas Tatanan Baru Transportasi: Bagi Indonesia Yang Maju Dan Sejahtera, UGM, Yogyakarta.

Prama, Gede. (Sabtu 14 April 2007), "Menyingkap Keindahan Bencana”, Kompas. Read, Herbert. (1968), The Meaning of Art, Praeger Publishers, New York Washington.

Sahman, Humar. (1993), Estetika Telaah Sistemik dan Historik, IKIP Semarang Press, Semarang.

Sidik, Fadjar. (1979) Disain Elementer, STSRI, ASRI, Yogyakarta.

Soedarso Sp. (2006), Trilogi Seni dan Keindahan, Penciptaan Eksistensi dan Kegunaan, Institut Seni Indonesia, Yogyakarta. . (1998), Seni dan Keindahan, Pidato Pengukuhan Jabatan Guru Besar Tetap pada Fakultas Seni Rupa Institut Seni Indonesia, Yogyakarta. . (2000), Sejarah Perkembangan Seni Modern, CV. Studio Delapan Puluh Enterprise, Jakarta.

Soedjono, Soeprapto. (2006), Pot-Pourri Fotografi, Universitas Tri Sakti, Jakarta.

Subroto Sm. (2006), "Fotografi Sebagai Media Ekspresi”, dalam Agus Burhan, Ed, Jaringan Makna Tradisi Hingga Kontemporer, BP ISI Yogyakarta, Yogyakarta.

Sugiarto, Atok. (2004), Fotografer Serba Bisa, Gramedia Pustaka Utama, Jakarta. Suharso. (2005), Kamus Bahasa Indonesia, CV. Widya Karya, Semarang. Sumardjo, Jakob. (2006), Estetika Paradoks, Sunan Ambu Press, STSI Bandung. Suseno, Franz Magnis. (2006), Menalar Tuhan, Kanisius, Yogyakarta.

Suwaji, Bastomi. (1992), Wawasan Seni, IKIP Semarang Press, Semarang. Worobiec, Tony. (2003), Photo Art, An Imprint Of Watson-Guptill Publications, New York. 